\title{
Effect of change in the psychosocial work environment on sickness absence: a seven year follow up of initially healthy employees
}

\author{
Jussi Vahtera, Mika Kivimäki, Jaana Pentti, Töres Theorell
}

\begin{abstract}
Study objective-To investigate the impact of changes in psychosocial work environment on subsequent sickness absence. Design-Analysis of questionnaire and sickness absence data collected in three time periods: 1990-1991, before the recession; 1993, worst slump during the recession; and 1993-1997, a period after changes.

Setting-Raisio, a town in south western Finland, during and after a period of economic decline.

Participants-530 municipal employees (138 men, 392 women) working during 1990-1997 who had no medically certified sick leaves in 1991. Mean length of follow up was 6.7 years.

Main results-After adjustment for the pre-recession levels, the changes in the job characteristics of the workers during the recession predicted their subsequent sick leaves. Lowered job control caused a 1.30 $(95 \% \mathrm{CI}=1.19,1.41)$ times higher risk of sick leave than an increase in job control. The corresponding figures in relation to decreased social support and increased job demands were $1.30(95 \% \mathrm{CI}=1.20$, $1.41)$ and $1.10(95 \% \mathrm{CI}=1.03,1.17)$, respectively. In some cases there was an interaction with socioeconomic status, changes in the job characteristics being stronger predictors of sick leaves for employees with a high income than for the others. The highest risks of sick leave (ranging from 1.40 to 1.90 ) were associated with combined effects related to poor levels of and negative changes in job control, job demands and social support.

Conclusion-Negative changes in psychosocial work environment have adverse effects on the health of employees. Those working in an unfavourable psychosocial environment before changes are at greatest risk.

(F Epidemiol Community Health 2000;54:484-493)
\end{abstract}

Several studies have demonstrated the association between the level of job characteristics and various aspects of health (for example, cardiovascular mortality and morbidity, sickness absence). ${ }^{1-10}$ Consequently, policy implications of prior studies have included strategies to change the work environment toward a direction in which the level of job characteristics indicates lower health risk. ${ }^{11}$ To be precise, however, evidence showing that a change in job characteristics is really followed by a change in health is still sparse.

Exposure to job characteristics, such as job control, job demands and social support at work, has been assessed in the studies of Johnson et $a l^{12}$ and Bosma et al. ${ }^{13}$ The first investigation showed that workers with low job control had a significantly higher relative risk for cardiovascular mortality than other workers, and that this risk varied slightly depending on the exposure time. However, workers exposed to both low control and low social support for a long period of time had the highest relative risk. By calculating the mean from the levels of job characteristics obtained on two occasions, Bosma et $a l^{13}$ showed that the participants with high levels of control at both phases were at a lower risk of self reported disease than those having low job control on both occasions. The risk of disease in the intermediate exposure group was between those found in the two above mentioned groups. The intermediate group included participants with stable intermediate job control and those who changed from low to high job control, as well as those who changed from high to low job control between the phases.

Instead of exposure, Theorell et $a l^{14}$ focused on changes in the psychosocial work environment by comparing the levels of job characteristics 10 years before and one year before the first myocardial infarction in a casereferent study. A decrease in job control during the 10 years preceding the infarction, as indicated by a transition to a lower job status, was associated with increased risk after adjustments for demographic, biological and behavioural risk factors. Corresponding results were not obtained in relation to job demands.

In addition to these epidemiological studies, some laboratory and field experiments and cross sectional studies have demonstrated physiological responses and changes in self reported well being after implementation of work related interventions or changes in working conditions. ${ }^{15-20}$

Despite the large number of empirical studies, several open questions remain. Firstly, research on exposure to an adverse work environment did not specify how changes in job characteristics-either positive or negativemay affect the development of health. Secondly, in the study of Theorell et $a l^{14}$ the direction of changes was indicated. However, 
the data on these changes were derived from a trajectory of job status that may indicate not only modifications in job characteristics but also in income, socioeconomic status and other health related factors. Thirdly, experiments were restricted in terms of follow up time (not exceeding one year) and health indicators (physiological reactions and self reports) giving therefore only minimal information about changing risks of disease in relation to interventions.

To eliminate some of these limitations, we took advantage of a naturalistic situation that permitted direct comparison of the effects of different work situations on the health of Finnish municipal employees in 1990-1997. During these years, Finland faced its most severe economic decline since the first world war. ${ }^{21}$ As a consequence, reductions of personnel, reorganisations and other major changes in work took place in many occupations and workplaces. ${ }^{22}$ We examined how these variations predicted the development of sickness in a sample of initially healthy employees.

\section{Methods}

The participants were 530 full time municipal employees (138 men, 392 women) working during 1990-1997 in the service of the town of Raisio, in south western Finland. We used the employer's records to identify 981 employees in Raisio who had worked for at least six months in 1991 before major changes, and for at least six months in 1993 when the most extensive reductions in personnel occurred. Of these employees, we selected all those ( $\mathrm{n}=674$ ) who had no medically certified sick leaves in 1991, representing the healthy cohort at the beginning of the study. Altogether $530(79 \%)$ of them agreed to participate in the study and responded to the surveys in 1990 and 1993. None of the respondents rated their health as poor in the first survey. After adjusting for demographic characteristics, there were no differences in sickness absence rates in 1993-1997 between the respondents and the non-respondents. The occupations of the participants ranged from higher grade white collar workers (for example, managers, physicians, teachers), lower grade white collar workers (for example, technicians, registered nurses, office workers) to blue collar workers (for example, cleaners, maintenance workers, institution kitchen assistant).

As a consequence of the economic recession, contacted days worked by municipal employees in Raisio fell by $14.5 \%$ between 1991 and $1993 .{ }^{22}$ Staff numbers were reduced partly through retirement and partly through not filling vacancies. Savings were also gained by not hiring cover for those absent from work. Only employees without permanent contracts of employment lost jobs. The reduction was greater among women $(16 \%)$ than among men $(10 \%)$. At the same time, the age profile of employees changed greatly. Contracted days worked by those over 50 years of age rose from
$22 \%$ to $29 \%$ of all contracted days worked. After 1993, contracted days worked gradually increased but were still $5.7 \%$ lower in 1997 than in 1991.

The employer's records from 1 January 1991 to 31 December 1997 relating to medically certified sickness absences and the follow up times of these employees were analysed. For each employee, the number of contracted days worked was calculated by deducting the number of days absent from work between 1991 and 1997 from the total contracted days in those years. All causes of absence were noted except sickness. Thus, contracted days worked represented the periods of time during which sickness absences could emerge. The follow up time was 941 person years for men and 2611 person years for women. To increase comparability to prior research, ${ }^{4}$ some of the analyses were additionally performed in data including also employees with sick leaves in 1991 (189 men related to a follow up of 1275 person years; 575 women and 3792 person years).

We divided the data into three time periods: 1990, before the major changes (time 1), 1993, the worst point in the downsizing (time 2); and 1993-1997, when the downsizing had slowed down (time 3). Changes in self reported job characteristics were assessed using the information obtained by questionnaire surveys at times 1 and 2 . Job characteristics were measured by sets of questions relating to skill discretion (four items; Cronbach's $\alpha$ reliability $r=0.78$, range $6.3-100$ ), authority to make decisions (seven items; $r=$ 0.84 , range $0-100$ ), opportunities to participate in decision making (three items; $r=0.76$, range $0-100)$ and predictability in relation to work (four items; $r=0.67$, range 6.3-100), as elements in job control ${ }^{63-26}$; psychological demands of work (five items; $r=0.70$, range 15-100) and physical demands of work (three items; $r=0.55$, range $1.7-5)^{25}{ }^{26}$; and social support from superiors (nine items; $r=0.90$, range $1-5$ ) as well as from workmates (four items; $r=0.83$, range $1-5) .{ }^{27}$ An index for each job characteristic was calculated by summing the scores derived from the questionnaire responses. A higher sum score indicated a higher level of job characteristics. The internal consistency of the measure of physical demands was rather low weakening its predictive power. All the measures were normally distributed. The time 1 scores were standardised and the means and standard deviations related to these scores were used to standardise the respective time 2 scores. The change in each self reported job characteristic was calculated by subtracting the score at time 2 from the score at time 1 . To reduce bias arising from differences in reactivity or styles of response between people, we also used aggregated scores calculated from the index scores of job characteristics among all the respondents, including also those who had lost or left their jobs between times 1 and 2 and/or who had been on sick leaves in 1991 ( $\mathrm{n}=1110$ at time 1 and $n=812$ at time 2). In the measures of 
job control and job demands, we aggregated scores for each occupational group, classified according to Statistics Finland ${ }^{28}$; for the measures of social support, aggregate scores were calculated for each work place. The respective aggregate score was linked to each participant. The scores were standardised in the same way as the individual scores. The change in each aggregated job characteristic was calculated by subtracting the aggregate score at time 2 from the aggregate score at time 1 .

Data on sick leaves were collected from the records kept by the Raisio occupational health care unit. The records list the beginning and end dates of each sick leave for each employee. All certificates relating to sick leaves, irrespective of place of issue, must be forwarded for recording. Employees may fill out their own certificates for absences of three days or less. For absences of over three days, medical certificates are required. We dealt only with the number of long spells of sickness absence. They are strongly associated with other health measures and common predictors of health such as age, socioeconomic status and healthrisk behaviours. ${ }^{622262930}$ Regarding the corresponding associations with short spells, the results are mixed. ${ }^{22} 2630$ Thus, short spells may reflect more than long spells non-health related absence in addition to that driven by illness.

To identify employees with health problems at the beginning of the study (that is, employees who were excluded from the cohort), we recorded all sick leaves during time 1 (1 January to 31 December 1991). To study the effects of changes in job characteristics between times 1 and 2 on health at time 3, we grouped all 985 sick leaves that occurred after changes from 1 January 1993 to 31 December 1997. We checked the records for inconsistencies, and combined any overlapping or consecutive periods of sickness absence.

The procedures for recording sick leave in Finnish municipalities are reliable. Employees are paid their full salary during periods of sick leave. Employers receive compensation from the Finnish Social Insurance Institution for salaries paid to employees on sick leave after the first 10 days. To receive full compensation, the employers are required to keep strict records of sick leave.

Maternity leaves and absences attributable to caring for a sick child are not included in the sickness absences. Regulations concerning the work contracts made by Finnish municipalities allow an employee to be absent from work without interruptions in salary payment to care for their under 10 year old child with an acute illness. Each such absence spell is fully compensated up to three days, and there are no limitations in the number of the spells per employee per year. Thus, the participants had no reason to wrongly report being ill when staying at home to care for their own sick child.

We also investigated seven other potential predictors of sickness: sex; age; annual income status; behavioural risks such as smoking, alcohol consumption, and sedentariness; and overweight as a biological risk factor. ${ }^{622}{ }^{31}{ }^{32}$ Annual incomes were transformed logarithmically to assess differences in relative income and because of skewness of the measure. We determined whether the subjects smoked regularly (yes or no), the amount of alcohol consumed ( $\mathrm{g}$ of alcohol per week; high consumption defined as $>280 \mathrm{~g} /$ week in men, $>190 \mathrm{~g} /$ week in women), the amount of physical activity (sedentariness was defined as less than half an hour of rapid walking per week), and the body mass index (BMI) of each subject (overweight was defined as BMI $>27 \mathrm{~kg} / \mathrm{m}^{2}$ ).

DATA ANALYSES

As descriptive statistics, mean levels of job characteristics at times 1 and 2 were calculated, and the difference was tested by repeated measures analysis of variance. Interactions with sex, age and income were tested. The extent of the change in job characteristics between times 1 and 2 for each participant was calculated. We calculated the number of periods of sick leave and the follow up period in person years for each employee. Because the number of sick leaves is a form of count data, Poisson regression models were fitted to the data. ${ }^{22} 2933$ Use of the Poisson model implies that the between employee variance in the rates of sick leave is equal to the expected rate of sick leave. In this study, the dispersion in the rates of sick leave was close to that predicted from the Poisson model.

We used hierarchical Poisson regression models to estimate the strength of the relations of the level of job characteristics at time 1 , and change in job characteristics between times 1 and 2 to medically certified sick leaves at time 3. The rate of sick leaves per 100 person years and the corresponding rate ratios for predictors at high and low levels were calculated. As regards the job characteristics at time 1 , the cut off points for high and low level referred to +1 $\mathrm{SD}$ and $-1 \mathrm{SD}$, respectively. Concerning the change in job characteristics, high and low levels referred to the magnitude of change in job characteristics +0.5 SD between times 1 and 2 . The levels of and changes in job characteristics were treated as continuous variables in all analyses. We adjusted rate ratios and their $95 \%$ confidence intervals (CI) for behavioural and biological risk factors. When studying the association between the change in job characteristics and sick leave, we additionally adjusted the rate ratios for the level of job characteristics at phase 1 . We tested the effects of demographics (that, sex, age (18-41 years, $n=267,42-63$ years, $n=263$ ) and income (above the mean, $n$ $=279$, below the mean, $n=251)$ ) on the relation between levels of changes in job characteristics and periods of sick leave by using a cross product term as recommended by Cohen and Cohen. ${ }^{34}$ Correspondingly, a set of moderated hierarchical Poisson regression analyses were performed to estimate the joint effects of the level of job characteristics at time 1 and change in job characteristics between times 1 and 2 on sick leave at time 3 by entering a cross product term "level of job characteristics $\mathrm{X}$ change in job characteristics". Finally, appropriate 
Table 1 Percentage of participants according to degree of change in self reported characteristics of the psychosocial work environment

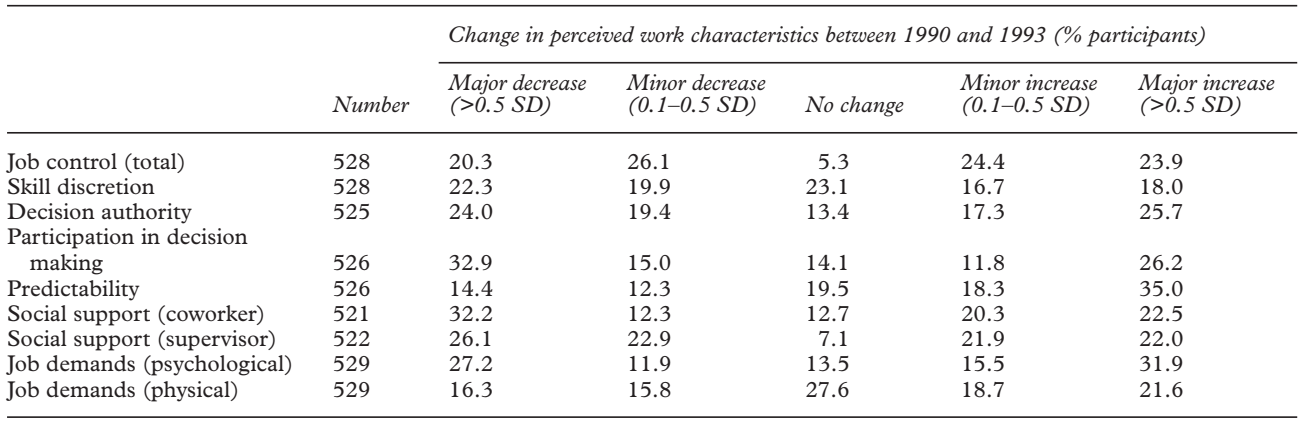

second level interactions with sex, age, and income were tested separately.

We used the SAS program package for all analyses. Poisson regression models were calculated using the GENMOD procedure..$^{35}$

\section{Results}

Job characteristics were perceived in a more favourable way in the initially healthy sample than among employees with sick leaves at time 1. For example, the mean of job control was 61.24 in the first sample but only 57.12 in the latter sample $(t=3.76, \mathrm{p}<.001)$.

In the initially healthy sample, a large number of participants was exposed to major changes, both negative and positive, between times 1 and time 2 (table 1 ). There were several differences in the level of job characteristics between the participants. The level of skill discretion and opportunities to participate in decision making decreased, and predictability in relation to work and physical demands (only in employees with a high income) increased between times 1 and 2 (table 2).
Before adjustments, all the job characteristics at time 1 predicted sick leave at time 3, except for decision authority and supervisory support (table 3). In no case was their effect dependent on sex or age. Adjustments for behavioural and biological risk factors did not change these figures significantly.

The analyses performed for the sample containing also those employees who had been on sick leave at time 1 showed significantly higher associations between job characteristics and sickness absence (for example, in a fully adjusted Poisson regression model including adjustment for sick leaves before change, the risk of sick leave was $1.37(1.22,1.54)$ times higher in employees with poor job control than in employees with strong job control. The corresponding risk observed in the initially healthy cohort was $1.24(1.09,1.41)$ ).

After adjustment for the level of job characteristics at time 1 , the change in them between times 1 and 2 significantly predicted sick leaves at time 3 (table 3 ). Considering self reported measures, a change in every job characteristic

Table 2 Mean level of psychosocial work characteristics

\begin{tabular}{|c|c|c|c|c|c|c|c|c|c|c|}
\hline & \multicolumn{10}{|c|}{ Difference betweent } \\
\hline & \multicolumn{3}{|l|}{ Gender } & \multicolumn{3}{|c|}{ Age group } & \multicolumn{3}{|c|}{ SES group } & \multirow{2}{*}{$\begin{array}{l}\text { Time } \neq \\
F \text { value } \\
\text { (1.530) }\end{array}$} \\
\hline & $\begin{array}{l}\text { Men } \\
(n=138)\end{array}$ & $\begin{array}{l}\text { Women } \\
(n=392)\end{array}$ & $\begin{array}{l}\text { F value } \\
(1.530)\end{array}$ & $\begin{array}{l}18-41 \\
(n=267)\end{array}$ & $\begin{array}{l}42-63 \\
(n=263)\end{array}$ & $\begin{array}{l}\text { F value } \\
(1.530)\end{array}$ & $\begin{array}{l}\text { Low } \\
(n=251)\end{array}$ & $\begin{array}{l}\text { High } \\
(n=279)\end{array}$ & $\begin{array}{c}F \text { value } \\
(1.530)\end{array}$ & \\
\hline Job control (total) & & & 0.3 & & & 2.4 & & & $10.8^{\star \star}$ & 0.3 \\
\hline 1990 & 60.0 & 61.7 & & 62.0 & 60.4 & & 59.2 & 63.0 & & \\
\hline 1993 & 61.8 & 61.4 & & 62.4 & 60.5 & & 59.7 & 63.1 & & \\
\hline Skill discretion & & & 1.6 & & & $4.3^{\star}$ & & & $22.9^{\star \star \star}$ & $4.3^{\star}$ \\
\hline 1990 & 71.3 & 73.8 & & 74.5 & 71.8 & & 70.0 & 76.0 & & \\
\hline 1993 & 71.1 & 72.3 & & 73.3 & 70.6 & & 68.6 & 74.9 & & \\
\hline Decision authority & & & 0.6 & & & 2.3 & & & 0.1 & 0.3 \\
\hline 1990 & 54.7 & 57.5 & & 58.0 & 55.5 & & 56.6 & 56.9 & & \\
\hline 1993 & 57.1 & 57.2 & & 58.4 & 55.9 & & 57.8 & 56.7 & & \\
\hline Participation in decision making & & & 0.4 & & & 0.1 & & & $21.2^{\star \star \star}$ & $8.2^{\star \star}$ \\
\hline 1990 & 48.6 & 49.7 & & 49.4 & 49.4 & & 46.0 & 52.4 & & \\
\hline 1993 & 49.6 & 46.1 & & 47.6 & 46.4 & & 42.6 & 50.9 & & \\
\hline Predictability & & & 0.0 & & & 0.5 & & & $10.5^{\star \star}$ & $42.6^{\star \star \star}$ \\
\hline 1990 & 67.7 & 67.4 & & 67.8 & 67.2 & & 65.2 & 70.0 & & \\
\hline 1993 & 71.4 & 71.7 & & 72.0 & 71.2 & & 70.1 & 72.9 & & \\
\hline Social support (coworker) & & & $8.4^{\star \star}$ & & & $6.5^{\star}$ & & & 1.7 & 0.1 \\
\hline 1990 & 3.25 & 3.48 & & 3.32 & 3.52 & & 3.40 & 3.44 & & \\
\hline 1993 & 3.26 & 3.47 & & 3.35 & 3.48 & & 3.34 & 3.47 & & \\
\hline Social support (supervisor) & & & 0.8 & & & 0.2 & & & 3.2 & 1.6 \\
\hline 1990 & 3.40 & 3.43 & & 3.41 & 3.44 & & 3.47 & 3.38 & & \\
\hline 1993 & 3.31 & 3.41 & & 3.42 & 3.34 & & 3.45 & 3.32 & & \\
\hline Job demands (psychological) & & & 0.0 & & & 0.6 & & & $13.3^{\star \star \star}$ & 2.1 \\
\hline 1990 & 58.3 & 58.6 & & 57.7 & 59.4 & & 57.2 & 59.7 & & \\
\hline 1993 & 60.0 & 59.4 & & 59.5 & 59.6 & & 56.8 & 62.0 & & \\
\hline Job demands (physical) $\$ & & & 2.4 & & & $7.0^{\star \star}$ & & & $6.1^{\star}$ & 3.3 \\
\hline 1990 & 3.11 & 3.23 & & 3.12 & 3.27 & & 3.29 & 3.11 & & \\
\hline 1993 & 3.21 & 3.26 & & 3.19 & 3.30 & & 3.27 & 3.22 & & \\
\hline
\end{tabular}

†Repeated measures analysis of variance. $¥$ Between 1990 and 1993. §Significant interaction between SES and change. ${ }^{\star} \mathrm{p}<0.05 ;{ }^{\star \star} \mathrm{p}<0.001 ;{ }^{\star \star \star} \mathrm{p}<0.0001$. 


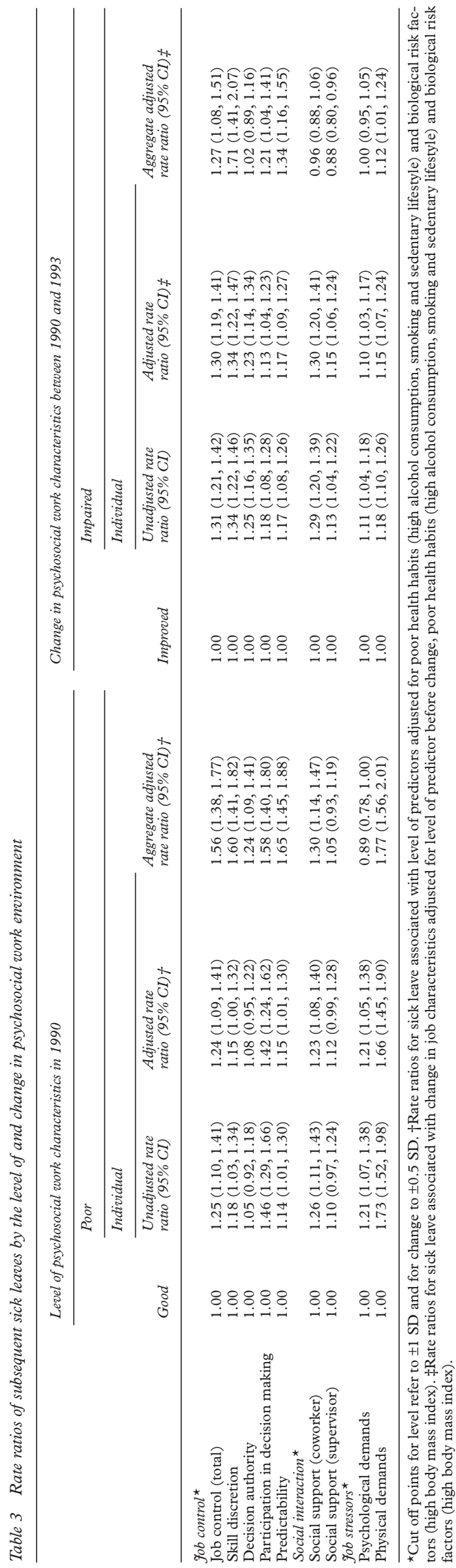

was predictive of sickness absences. In relation to aggregated measures, reductions in job control or in its dimensions, except for decision authority, as well as an increase in physical demands associated with heightened health risk.

We tested whether the sick leaves at phase 3 could be explained by exposure to an adverse work environment between times 1 and 2 . The average of the levels of job characteristics at times 1 and 2, indicating exposure, was a significant predictor of forthcoming sick leaves. However, the models including the level of exposure to job control or social support did not predict sickness absence as effectively as the models including the baseline level and changes in the corresponding job characteristics. For example, exposure to poor job control explained a $63 \%$ lower variance in sick leaves than the baseline level adjusted changes in job control (explained variance in sick leaves by the exposure model was $2.4 \%$ and by the change model $4.0 \%$ ). For coworker support, the respective difference was $39 \%$. Only in one case-that is, participation in decision making-exposure to job stressors explained an equal amount of variance in sickness absences as the change in them.

In relation to the effects of changes in job characteristics, several interactions with sex, age and income were detected (table 4). For example, decreased job control was a greater health risk for employees at 42-63 years of age and those with a higher than average income and impaired discretion relating to skills and reduced coworker support were greater risks for women than for men.

In six cases, the joint effects of the level of a job characteristic at time 1 and a change in another job characteristic between times 1 and 2 on sick leaves at time 3 were evident (fig 1). Health risk was highest in the following combinations of the dimensions of psychosocial work environment: poor job control or decision authority at baseline combined with decreasing supervisory support; high physical demands at baseline, together with decreased coworker or supervisory support; low supervisory support at baseline combined with reduction in skill discretion or decision authority. In no cases was the interaction dependent on sex or age.

Finally, in five cases the interaction between a job characteristic at time 1 and a change in another job characteristic between times 1 and 2 was dependent on SES (table 5). In general, the joint effects of job characteristics on sickness absence were stronger for employees with a high income than for those with a low income. In no cases, was the interaction dependent on sex or age.

\section{Discussion}

We explored how changes in the psychosocial work environment were associated with the subsequent development of illnesses in an initially healthy sample of employees. We focused on the gap between prior policy implications and the empirical evidence on which these implications are based. Although reductions in adverse psychosocial job characteristics 
Table 4 Influence of sex, age and SES on the relation between change in psychosocial work environment and subsequent sick leaves

\begin{tabular}{|c|c|c|c|c|c|c|c|c|c|}
\hline & $\begin{array}{l}\text { Men Adjusted } \\
\text { rate ratio } \\
(95 \% \text { CI }) t\end{array}$ & $\begin{array}{l}\text { Women Adjusted } \\
\text { rate ratio } \\
(95 \% \text { CI })+\end{array}$ & $\begin{array}{l}\text { Test for } \\
\text { interaction }\end{array}$ & $\begin{array}{l}\text { Age } 18-41 \\
\text { years } \text { Adjusted } \\
\text { rate ratio } \\
(95 \% C I) t\end{array}$ & $\begin{array}{l}\text { Age } 42-63 \\
\text { years Adjusted } \\
\text { rate ratio } \\
(95 \% C I)+\end{array}$ & $\begin{array}{l}\text { Test for } \\
\text { interaction }\end{array}$ & $\begin{array}{l}\text { Low income } \\
\text { Adjusted rate ratio } \\
(95 \% \text { CI })+\end{array}$ & $\begin{array}{l}\text { High income } \\
\text { Adjusted rate ratio } \\
(95 \% \mathrm{CI}) t\end{array}$ & $\begin{array}{l}\text { Test for } \\
\text { interaction }\end{array}$ \\
\hline Job control (total)^ & & & NS & & & $\mathrm{p}=0.001$ & & & $\mathrm{p}=0.037$ \\
\hline Improved & & & & 1.00 & 1.00 & & 1.00 & 1.00 & \\
\hline Impaired & & & & $\begin{array}{l}1.17(1.04, \\
1.31)\end{array}$ & $\begin{array}{l}1.54(1.35 \\
1.76)\end{array}$ & & $1.20(1.08,1.33)$ & $1.48(1.27,1.72)$ & \\
\hline Skill discretion ${ }^{\star}$ & & & $\mathrm{p}=0.024$ & & & NS & & & NS \\
\hline Improved & 1.00 & 1.00 & & - & - & & - & - & \\
\hline Impaired & $\begin{array}{l}1.16(0.93, \\
1.44)\end{array}$ & $\begin{array}{l}1.39(1.26, \\
1.53)\end{array}$ & & & & & & & \\
\hline Decision authority* & & & NS & & & $\mathrm{p}=0.041$ & & & NS \\
\hline Improved & & & & 1.00 & 1.00 & & - & - & \\
\hline Impaired & & & & $\begin{array}{l}1.17(1.05, \\
1.30)\end{array}$ & $\begin{array}{l}1.34(1.19 \\
1.51)\end{array}$ & & & & \\
\hline $\begin{array}{l}\text { Possibilities for } \\
\text { participation }\end{array}$ & & & NS & & & $\mathrm{p}=0.003$ & & & $\mathrm{p}=0.012$ \\
\hline Improved & & & & 1.00 & 1.00 & & 1.00 & 1.00 & \\
\hline Impaired & & & & $\begin{array}{l}1.09(0.90, \\
1.13)\end{array}$ & $\begin{array}{l}1.31(1.15, \\
1.49)\end{array}$ & & $0.99(0.88,1.11)$ & $1.25(1.09,1.43)$ & \\
\hline Predictability ${ }^{\star}$ & & & NS & & & NS & & & $\mathrm{p}=0.047$ \\
\hline Improved & & & & & & & 1.00 & 1.00 & \\
\hline Impaired & & & & & & & $1.09(0.99,1.21)$ & $1.30(1.15,1.47)$ & \\
\hline Social support (coworker) ${ }^{\star}$ & & & $\mathrm{p}=0.021$ & & & NS & & & NS \\
\hline Improved & 1.00 & 1.00 & & - & - & & - & - & \\
\hline Impaired & $\begin{array}{l}1.18(0.99, \\
1.41)\end{array}$ & $\begin{array}{l}1.37(1.25, \\
1.49)\end{array}$ & & & & & & & \\
\hline $\begin{array}{l}\text { Social support } \\
\text { (supervisor) }^{\star}\end{array}$ & & & NS & & & $\mathrm{p}=0.045$ & & & NS \\
\hline Improved & & & & 1.00 & 1.00 & & - & - & \\
\hline Impaired & & & & $\begin{array}{l}1.04(0.93 \\
1.17)\end{array}$ & $\begin{array}{l}1.25(1.12, \\
1.40)\end{array}$ & & & & \\
\hline Social support (coworker)* & & & $\mathrm{p}=0.021$ & & & NS & & & NS \\
\hline Improved & 1.00 & 1.00 & & - & - & & - & - & \\
\hline Impaired & $\begin{array}{l}1.18(0.99 \\
1.41)\end{array}$ & $\begin{array}{l}1.37(1.25, \\
1.49)\end{array}$ & & & & & & & \\
\hline $\begin{array}{l}\text { Job demands } \\
\text { (psychological)* }^{\star}\end{array}$ & & & NS & & & NS & & & NS \\
\hline $\begin{array}{l}\text { Increased } \\
\text { Decreased }\end{array}$ & - & - & & - & - & & - & - & \\
\hline Job demands (physical) ${ }^{\star}$ & & & NS & & & NS & & & NS \\
\hline $\begin{array}{l}\text { Increased } \\
\text { Decreased }\end{array}$ & - & - & & - & - & & - & - & \\
\hline
\end{tabular}

${ }^{\star}$ Cut off points refer to an increase of +0.5 SD compared with a decrease of $-0.5 \mathrm{SD}$. $†$ Rate ratios and their $95 \%$ confidence intervals adjusted for level of predictor before change, poor health habits (high alcohol consumption, smoking and sedentary lifestyle) and biological risk factors (high body mass index).

have often been called for by researchers, there has been a lack of epidemiological data indicating that such alterations indeed are helpful. Our findings suggest that changes in work characteristics, such as job control, job demands and social support at work are important predictors of sickness.

Sickness absence has frequently been used as an indicator of employee health, although the decision to stay away from work is also likely to be influenced by a number of attitudinal and social factors (for example, indispensability at work, potential risk of wage reduction, family responsibilities, and informal norms of workmates regarding acceptance levels of absence). To minimise the effect of these confounding factors, we considered only medically certified sick leaves. According to Marmot and his colleagues, ${ }^{30}$ medically certified sickness absences serve as a measure of health in the working population when health is understood as a mixture of social, psychological and physiological functioning. Thus, our data reflect the development of health in general but do not provide information on specific diseases.

Consistently with numerous studies, ${ }^{1-10}{ }^{36}$ we found that the level of work characteristics was related to health problems. New medically certified sick leaves were more common in people who had a job with low job control, poor co- worker support, high psychological demands or high physical demands. However, the magnitude of the association between job characteristics and sick leave was slightly lower than that reported in previous research on sickness absenteeism. ${ }^{429}$ For example, the rates of long spells of sickness absence in low job control compared with high job control reported by North et $a l^{4}$ were $25 \%$ higher than those observed in this study. This may reflect differences in the samples. By including only people with no medically certified sick leaves at baseline and at least average self rated health status at that time, we applied a more stringent inclusion criterion than that in earlier studies of sickness absence. When we performed the analyses for the total sample, using the same inclusion criterion as researchers in the other studies, the ratio for the rates of sick leave in an adverse psychosocial work environment compared with a favourable one was similar to those reported previously. Although exclusion of the employees with baseline sickness from the sample increased the validity of our study design, it also significantly constricted the variance in job characteristics and therefore decreased their power to predict sick leaves. It is also possible that employees with poor health are more vulnerable to the effects of an adverse psychosocial work environment. ${ }^{622}$ For these reasons, the present results may represent an 


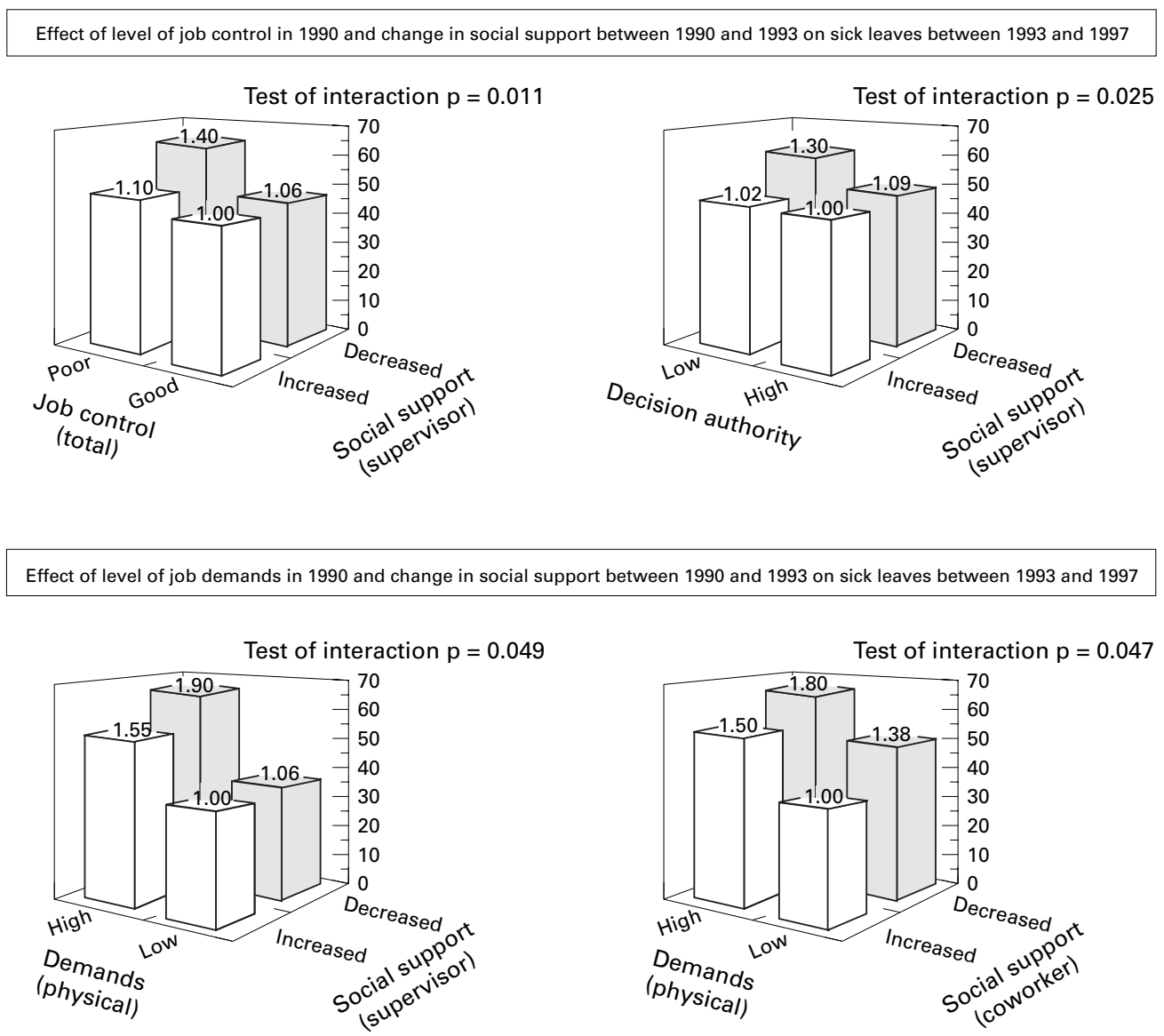

Effect of level of social support in 1990 and change in job control between 1990 and 1993 on sick leaves between 1993 and 1997

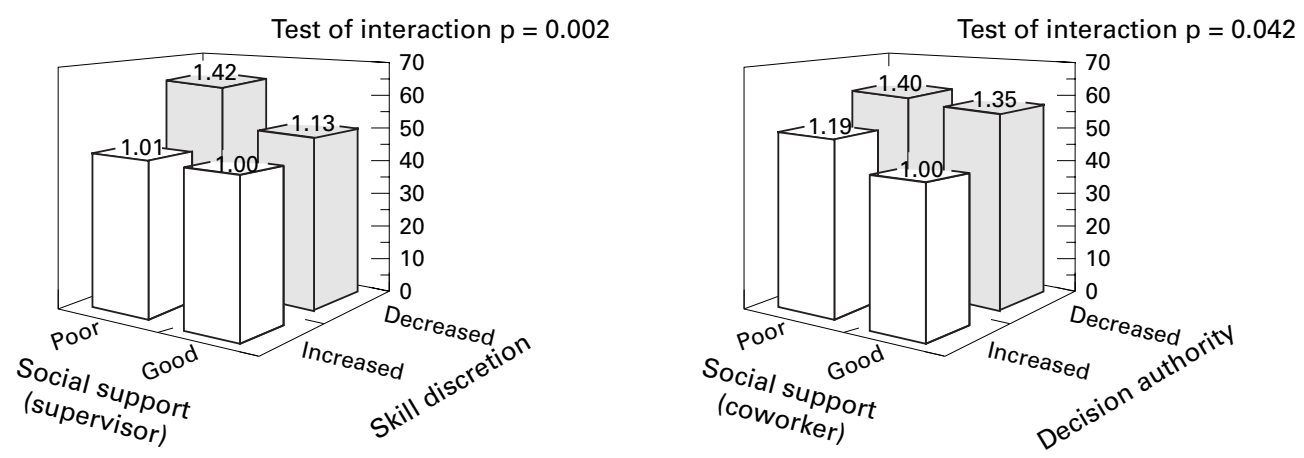

Figure 1 Interaction between level of and change in psychosocial work characteristics on the rates of subsequent sick leave (sick leave per 100 person years adjusted for sex, age, SES, poor health habits (high alcohol consumption, smoking and sedentary lifestyle) and biological risk factors (high body mass index).

underestimation of the actual extent of the effect of the levels of psychosocial work characteristics on health.

In addition to the level of job characteristics at a certain point of time, prior research has determined the health risks related to various exposures to these characteristics. ${ }^{12}{ }^{13}$ Exposure to these characteristics may be identical for people facing a decrease in a job characteristic from a high level to a lower level, for people with a stable intermediate level of a job charac- teristic and for persons experiencing an increase in the same job characteristic from a low level to a higher level. In a recent Whitehall II study by Bosma et al, ${ }^{13}$ for example, such cases were collapsed under the same category of intermediate level of exposure. Our findings do not suggest that such a procedure is an ideal one. After adjustment for the baseline level of the psychosocial work environment, a change in it led to different health risks depending on the direction of the change. Health problems 
Table 5 Interaction between level of and change in psychosocial work environment in employees with low and high SES

\begin{tabular}{|c|c|c|c|c|c|c|}
\hline \multicolumn{2}{|l|}{ Combination of psychosocial predictors } & \multicolumn{4}{|l|}{$S E S$} & \multirow[b]{3}{*}{$\begin{array}{l}\text { Test for } \\
\text { interaction }\end{array}$} \\
\hline & & \multicolumn{2}{|c|}{ Low income } & \multicolumn{2}{|c|}{ High income } & \\
\hline Level in 1990 & Change between 1990 and 1993 & $\begin{array}{l}\text { Absence } \\
\text { rate }^{\star}\end{array}$ & $\begin{array}{l}\text { Rate } \\
\text { ratio }\end{array}$ & $\begin{array}{l}\text { Absence } \\
\text { rate* }\end{array}$ & $\begin{array}{l}\text { Rate } \\
\text { ratio }\end{array}$ & \\
\hline Participation in decision making $†$ & Job demands (psychological) $\ddagger$ & & & & & $\mathrm{p}=0.031$ \\
\hline Good & Decreased & 33.9 & 1.00 & 23.2 & 1.00 & \\
\hline Good & Increased & 41.0 & 1.21 & 23.9 & 1.03 & \\
\hline Poor & Decreased & 44.0 & 1.30 & 25.4 & 1.09 & \\
\hline Poor & Increased & 49.4 & 1.46 & 32.3 & 1.39 & \\
\hline Skill discretion $\dagger$ & Job demands (physical) $\ddagger$ & & & & & $\mathrm{p}=0.007$ \\
\hline Good & Decreased & 47.8 & 1.00 & 24.1 & 1.00 & \\
\hline Good & Increased & 49.6 & 1.04 & 29.1 & 1.21 & \\
\hline Poor & Decreased & 40.1 & 0.84 & 31.2 & 1.29 & \\
\hline Poor & Increased & 55.6 & 1.16 & 33.4 & 1.39 & \\
\hline Job demands $\dagger$ & Job control (total) $\ddagger$ & & & & & $\mathrm{p}=0.029$ \\
\hline Low & Improved & 36.5 & 1.00 & 15.2 & 1.00 & \\
\hline Low & Impaired & 40.2 & 1.10 & 24.9 & 1.64 & \\
\hline High & Improved & 38.4 & 1.05 & 21.8 & 1.43 & \\
\hline High & Impaired & 52.5 & 1.44 & 29.4 & 1.93 & \\
\hline Job demands $\dagger$ & Skill discretion $\ddagger$ & & & & & $\mathrm{p}<0.001$ \\
\hline Low & Improved & 36.8 & 1.00 & 13.0 & 1.00 & \\
\hline Low & Impaired & 39.7 & 1.08 & 23.7 & 1.83 & \\
\hline High & Improved & 35.4 & 0.96 & 25.8 & 1.98 & \\
\hline High & Impaired & 48.2 & 1.31 & 30.1 & 2.32 & \\
\hline Job demands† & Participation in decision making $\neq$ & & & & & $\mathrm{p}=0.004$ \\
\hline Low & Improved & 47.5 & 1.00 & 17.4 & 1.00 & \\
\hline Low & Impaired & 41.8 & 0.88 & 25.0 & 1.44 & \\
\hline High & Improved & 43.8 & 0.92 & 26.5 & 1.52 & \\
\hline High & Impaired & 50.4 & 1.06 & 29.4 & 1.69 & \\
\hline
\end{tabular}

^Absence rate per 100 person years adjusted for poor health habits (high alcohol consumption, smoking and sedentary lifestyle) and biological risk factors (high body mass index). $†$ Cut off points for level refer to $\pm 1 \mathrm{SD}$. $\ddagger$ Cut off points for change refer to $\pm 0.5 \mathrm{SD}$. Interaction between level of a job characteristic, change in a job characteristic and SES.

seem to be more precisely predictable by taking into account the direction of change in the psychosocial work environment, rather than by simply averaging the levels of the job characteristics at two times as a measure of exposure.

It is possible that changes in job characteristics may contribute to the development of health problems indirectly through alteration in a person's socioeconomic position. While this may be true in studies using occupation related inferred measures of job characteristics, ${ }^{14}$ it is not a probable explanation for our findings. In this study, changes in job characteristics did not associate with job transitions, and only $3 \%$ of the participants had a different job within the service of the town of Raisio after the recession.

It may also be questioned whether the negative change in self rated job characteristics was a consequence of the sick leaves rather than its predecessor. Our results, which are derived from a sample of healthy employees before changes, speak against this interpretation. Confounding attributable to differences in traditional health risks, such as regular smoking, excessive alcohol consumption, a sedentary lifestyle, and overweight are not probable, either. The findings remained similar after statistically controlling the effects of these behavioural and biological health risks. This implies that the effects of changes in job characteristics are not likely to be mediated by such risks within the seven year follow up. $^{637}$

While the effects of changes in job characteristics did not significantly differ between men and women, or across different age groups, they were dependent on socioeconomic position. The health effects were greater for employees with a high income than for the others. This is an interesting finding because the literature suggests that adverse changes in health are more common among persons of low socioeconomic position..$^{22} 38$ In addition, earlier studies on the Raisio sample show that the reduction in contracted days worked was greater in employees with a low income. Despite this, major downsizing was associated with higher risk of absence for employees with higher incomes. ${ }^{62}$ This combined with the present finding contradicts the argument that psychosocial job characteristics and their change reflect merely social position or its change.

The joint effects of psychosocial work features have long been a matter of controversy. The majority of the studies have shown an additive effect pattern of job characteristics on ill health. ${ }^{11}$ However, theoretical models and some empirical studies suggest an interactional effect pattern. ${ }^{26}{ }^{39-41}$ Our observations support the latter hypothesis. We obtained several true multiplicative interactions between the levels of psychosocial characteristics and the changes in them. Their effects on health were as expected on the basis of theoretical models, such as the job strain model and the iso-strain model. ${ }^{25} 39{ }^{41}$ The combination of poor psychosocial work characteristics and an adverse change in some other psychosocial factor of the work environment was associated with the greatest risk of subsequent illness. In contrast, an initially favourable work environment in which some job characteristics were further improved was related to the lowest risk of health problems. Compensatory effects were also found. A favourable change in one feature of the 
KEY POINTS

- Negative changes in psychosocial work environment have adverse effects on the health of employees.

- The combination of poor psychosocial work characteristics and an adverse change in some other psychosocial factor of the work environment was associated with the greatest risk of subsequent illness.

- A favourable change in one feature of the psychosocial work environment partially buffered from the adverse consequences of other job characteristics.

- High or improving supervisory support seemed to be able to reduce a significant proportion of the excessive health risk associated with low or decreasing job control.

psychosocial work environment partially buffered from the adverse consequences of other job characteristics.

The results on joint effects have practical implications for the management during turbulent working conditions. In prior research on work characteristics, job control has been shown to be one of the strongest psychosocial predictors of sickness absence, morbidity and mortality. ${ }^{24}$ 6-8 10-14 Our findings suggest that the negative consequences of low job control can effectively be diminished, not only by increasing job control, but also by developing leadership. High or improving supervisory support seemed to be able to reduce a significant proportion of the excessive health risk associated with low or decreasing job control.

In conclusion, this study gave strong evidence on the potential health related effects of changing the psychosocial work environment. Favourable transitions in job characteristics, such as job control, job demands and social support at work, seem to reduce the risk of sickness among employees. This effect was relatively independent of age and sex. Finally, improvement in one job characteristic seems to buffer against adverse influences related to other aspects of the psychosocial work environment. All these conclusions imply that improving the psychosocial work environment or even some of its elements could decrease the risk of illness among the working population.

We thank Dr Marja Lampio from the occupational health care unit in Raisio for her help in collecting the data on sickness absenteeism.

Funding: the study has been supported by grants from the Finnish Work Environment Fund and Academy of Finland (project no 44968) for the second author.

Conflict of interest: none.

1 Broadhead WE, Kaplan BH, James SA, et al. The epidemiologic evidence for a relationship between social support and health. Am f Epidemiol 1983;117:521-37.

2 Johnson JV, Hall EM, Theorell T. Combined effects of job strain and social isolation on cardiovascular disease morbidity and mortality in a random sample of the Swedish male working population. Scand $\mathcal{F}$ Work Environ Health ish male working
3 Melamed S, Ben-Avi I, Luz J, et al. Objective and subjective work monotony: effects on job satisfaction, psychological distress, and absenteeism in blue-collar workers. $7 \mathrm{Appl}$ Psychol 1995;80:29-42.

4 North F, Syme SL, Feeney A, et al. Psychosocial work environment and sickness absence among British civil servants: The Whitehall II study. Am F Public Health 1996;86:33240.

5 Everson SA, Lynch JW, Chesney MA, et al. Interaction of workplace demands and cardiovascular reactivity in progression of carotid atherosclerosis: population based study. BMF 1997;314:553-8.

6 Kivimäki M, Vahtera J, Thomson J, et al. Psychosocial factors predicting employee sickness absence during economic decline. F Appl Psychol 1997; 82: 858-72.

7 Marmot MG, Bosma H, Hemingway H, et al. Contribution of job control and other risk factors to social variations in coronary heart disease incidence. Lancet 1997;350:235-9.

coronary heart disease incidence. Lancet 1997;350:235-9.
8 Lynch J, Krause N, Kaplan GA, et al. Workplace conditions, Lynch J, Krause N, Kaplan GA, et al. Workplace conditions,
socioeconomic status, and the risk of mortality and acute myocardial infarcation: the Kuopio ischemic heart disea risk factor study. Am F Public Health 1997;87:617-22.

9 Amick BC III, Kawachi I, Coakley EH, et al. Relationship of job strain and iso-strain to health status in a cohort of women in the United States. Scand $\mathcal{F}$ Work Environ Health 1998;24:54-61.

10 Bosma H, Peter R, Siegrist J, et al. Two alternative job stress models and the risk of coronary heart disease. Am F Public Health 1998;88:68-74.

11 Theorell T, Karasek RA. Current issues relating to psychosocial job strain and cardiovascular disease research. $f$ Occup Health Psychol 1996;1:9-26.

12 Johnson JV, Steward W, Hall EM, et al. Long-term psychosocial work environment and cardiovascular mortality

3 Bosma H, Marmot MG, Hemingway H, et al. Low job control and risk of coronary heart disease in Whitehall II (protrol and risk of coronary heart disease in Whitehal

14 Theorell T, Tsutsumi A, Hallquist J, et al, The SHEEP Study Group. Decision latitude, job strain, and myocardial infarction: a study of working men in Stockholm. Am $\mathcal{F}$ Public Health 1998;88:382-8.

15 Jackson SE. Participation in decision making as a strategy for reducing job-related strain. F Appl Psychol 1983;68:319

16 Steptoe A, Fieldman G, Evans O, et al. Control over work pace, jot strain and cardiovascular responses in middleaged men. F Hypertension 1993;11:751-9.

17 Theorell T, Perski, A, Åkerstedt T, et al. Changes in job strain in relation to changes in physiological state. Scand $\mathcal{F}$ Work Environ Health 1988;14:189-96.

18 Theorell T, Karasek RA, Eneroth P. Job strain variations in relation to plasma testosterone fluctuations in working men relation to plasma testosterone fluctuations in working

19 Karasek RA. Lower health risk with increased job control among white collar workers. fournal of Organizational Behaviour 1990;11:171-85.

20 Grossi G, Theorell T, Jurisoo M, et al. Psychophysiological correlates of organizational change and threat of unemployment among police inspectors. Integrative Physiology and Behavioral Medicine 1999;34:30-42.

21 Statistical yearbook of Finland 1998. Helsinki, Finland: Statistics Finland; 1998.

22 Vahtera J, Kivimäki M, Pentti J. Effect of organisational downsizing on health of employees. Lancet 1997;350:11248.

23 Aronsson G. Dimensions of control as related to work organization, stress, and health. Int $\mathcal{F}$ Health Serv 1989;19: $459-68$.

24 Frese M. Theoretical models of control and health. In: Sauter SL, Hurrell JJ Jr, Cooper CL, eds. Fob control and worker ter SL, Hurrell JJ Jr, Cooper CL, eds. Fo
health. New York: Wiley, 1989:107-28.

25 Karasek R, Theorell T. Stress, productivity and reconstruction of working life. New York: Basic Books, 1990.

26 Vahtera J, Uutela A, Pentti J. The effects of objective job demands on registered sickness absence spells: do personal, social and job-related resources act as moderators? Work and Stress 1996;19:286-308.

27 Lehto A-M. Quality of working life and equity. Helsinki, Finland: Statistics Finland, 1991.

8 Classification of occupations. Handbook no 14. Helsinki, Finland: Statistics Finland, 1987.

29 North F, Syme SL, Feeney A, et al. Explaining socioeconomic differences in sickness absence: the Whitehall II nomic differences in sickness.

30 Marmot MG, Feeney A, Shipley M, et al. Sickness absence as a measure of health status and functioning: from the UK Whitehall II study. F Epidemiol Community Health 1995;49: $124-30$

31 Kaprio J, Koskenvuo M, Langinvainio H, et al. Genetic influences on use and abuse of alcohol: A study of 5638 adult Finnish twin brothers. Alcohol Clin Exp Res 1987;11: 349-56

32 Kujala J, Kaprio J, Sarna S, et al. Relationship of leisure-time physical activity and mortality. The Finnish twin cohort. ҰAMA 1998;279:440-4.

33 McCullagh P, Nelder JA. Generalized linear models. London: Chapman and Hall, 1989.

34 Cohen J, Cohen P. Applied multiple regression/correlation analysis for the behavioral sciences. 2nd ed. Erlbaum, NJ: Hillsdale, 1983.

35 SAS Technical Report P-243, SAS/STAT Software: The genmod procedure, Release 6.09. Cary, NC: SAS Institute Inc, 1993. 
36 Pieper C, LaCroix A, Karasek RA. The relation of psychosocial dimensions of work with coronary heart disease risk factors: a meta-analysis of five United States data bases $A m$ 7 Epidemiol 1989;129:483-94.

37 Johansson G, Johnson JV, Hall EM. Smoking and sedentary behaviour as related to work organization. Soc Sci Med 1991;32:837-46.

38 Hemingway $\mathrm{H}$, Stafford $\mathrm{M}$, Stansfeld $\mathrm{S}$, et al. Is the SF-36 a valid measure of change in population health? Results from the Whitehall II study. BMf 1997;315 1273-9.
39 Karasek RA Jr. Job demands, job decision latitude, and mental strain: implications for job redesign. Administrative mental strain: implications for job red

40 Alfredsson L, Karasek R, Theorell T. Myocardial infarction risk and psychosocial work environment: an analysis of the male Swedish working force. Soc Sci Med 1982;16: 463-7.

41 Johnson JV, Hall EM. Job strain, work place social support, and cardiovascular disease: a cross-sectional study of a random sample of the Swedish working population. Am F Public Health 1988;78:1336-42. 